Article

\title{
Analysis of a Single-Phase Z-Source Inverter for Battery Discharging in Vehicle to Grid Applications
}

\author{
Yifan Yu, Qianfan Zhang *, Bin Liang, Xiaofei Liu and Shumei Cui \\ Institute of Electromagnetic and Electronic Technology, Harbin Institute of Technology, \\ Harbin 150001, China; E-Mails: yu_yifan@hit.edu.cn (Y.Y.); liangbinhit@gmail.com (B.L.); \\ liuxiaofei.hit@gmail.com (X.L.); cuism@hit.edu.cn (S.C.) \\ * Author to whom correspondence should be addressed; E-Mail: zhang_qianfan@hit.edu.cn; \\ Tel.: +86-451-86413611 ext. 8402.
}

Received: 20 September 2011; in revised form: 23 November 2011 / Accepted: 25 November 2011 / Published: 15 December 2011

\begin{abstract}
Vehicle to Grid technology allows the batteries of electric vehicles to operate as energy storage elements for renewable energy power systems. The Z-Source inverter is a new and attractive topology for the power electronics interface. In this paper, the equivalent DC-link voltage ripple of a single-phase Z-Source inverter for Vehicle to Grid applications is analyzed in this paper before deriving a general design approach for the Z-Source network. These theoretical findings, and design rule for a Z-Source network have been confirmed by computer simulations and a laboratory-implemented prototype.
\end{abstract}

Keywords: Vehicle to Grid; electric vehicle; Z-Source inverter

\section{Introduction}

Electric Vehicles (EV) have attracted widespread research interest worldwide due to their attractive contributions to reducing gasoline consumption and carbon dioxide emissions. A large-capacity battery which can be recharged from the public utility is required for long distance driving. Furthermore, a bi-directional power electronics interface allows the battery to operate as a Distributed Generator (DG) to supply power to the grid or vice versa. The reliability of the renewable energy system will be greatly enhanced with the vast untapped storage of EV fleets when connected to the grid [1], which is known as the Vehicle to Grid (V2G) technology. 
Power converters with high efficiency, good power quality, bidirectional power flow, low cost and compact size are in great demand to meet the requirements of Vehicle to Grid technology. The newly-presented Z-Source inverter [2] provides an attractive single-stage topology for both voltage boosting and inversion. The topology of single-phase full bridge Z-Source inverter is shown in Figure 1.

Figure 1. Single-phase full bridge Z-Source inverter.
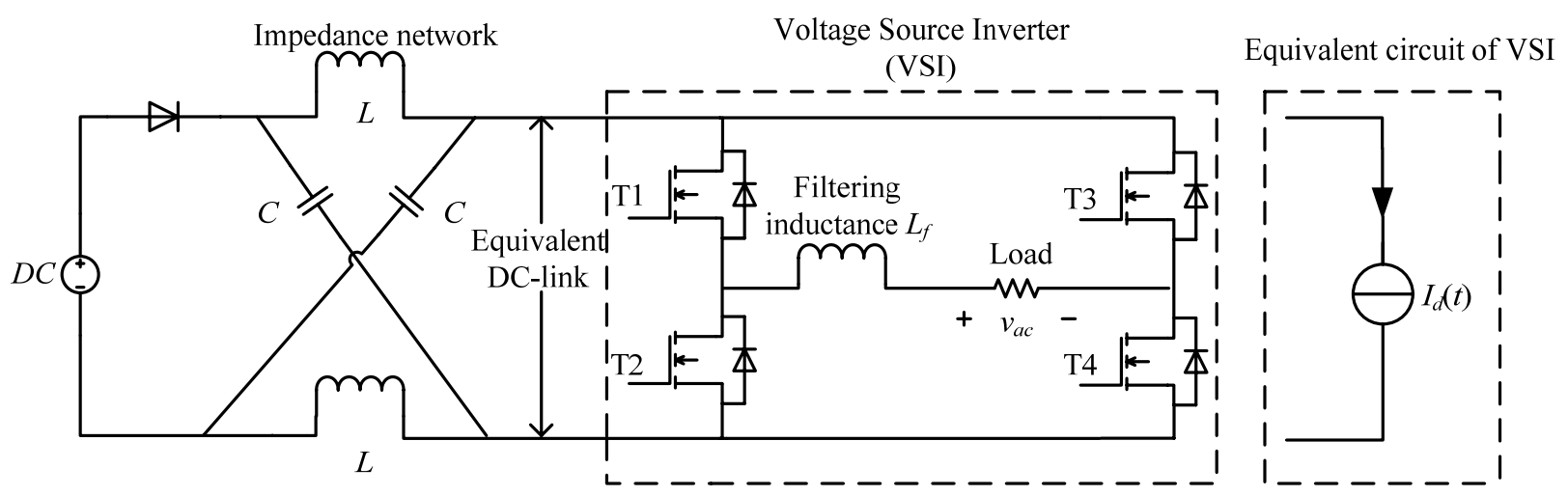

The DC-side of a conventional single-phase full bridge voltage source inverter is modified with a unique X-shape impedance network, which is known as the Z-Source network. Therefore, shoot-through state, which is strictly forbidden in conventional voltage source inverters, is allowed and implemented here for voltage boosting purposes. Since the capacitor in the Z-Source network may be charged to a higher voltage than the DC source, a diode is connected to prevent possible discharging. To realize the bidirectional power flow characteristic, the diode can be replaced with an IGBT with anti-paralleled diode to form a bidirectional Z-Source converter. Since this paper focuses on the discharging of batteries, a diode is used in the following analysis.

Large numbers of publications can be found regarding problems of pulse width modulation for this special shoot-through state [2-4], various modeling and control methods $[5,6]$ and possible applications [7-11]. The equivalent DC-link voltage ripple of Z-Source inverter is one of major concerns since it is directly related to inverter output power quality. The steady state operation and equivalent DC-link voltage ripple of three-phase Z-Source inverters have been investigated in detail [12]. Nevertheless, single-phase utility connections are more common in households and the equivalent DC-link voltage ripple of a single-phase Z-Source inverter has not been reported so far. Therefore, to fill this gap, the equivalent DC-link voltage ripple of a single-phase Z-Source inverter is analyzed in this paper before deriving a general design approach for the Z-Source network.

\section{DC Side Current of Single-Phase ZSI}

Several pulse width modulation techniques are available so far for the Z-Source inverter, including Simple Boost Control [2], Maximum Boost Control [3] and Constant Maximum Boost Control [4]. Simple Boost Control, which is generally used for its easy implementation, is described in Figures 2 and 3. 
Figure 2. Simple boost control of single-phase ZSI.

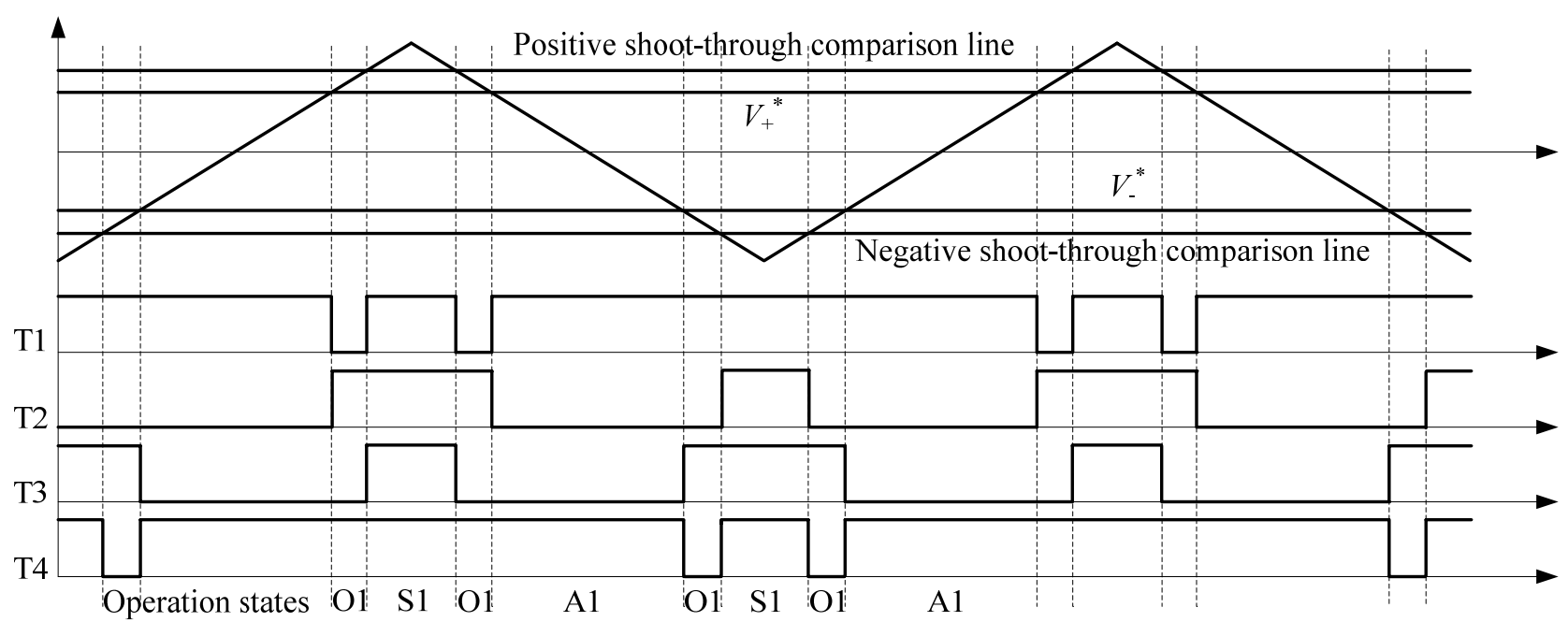

Figure 3. (a) Active-1 State; (b) Shoot-through-1 State.

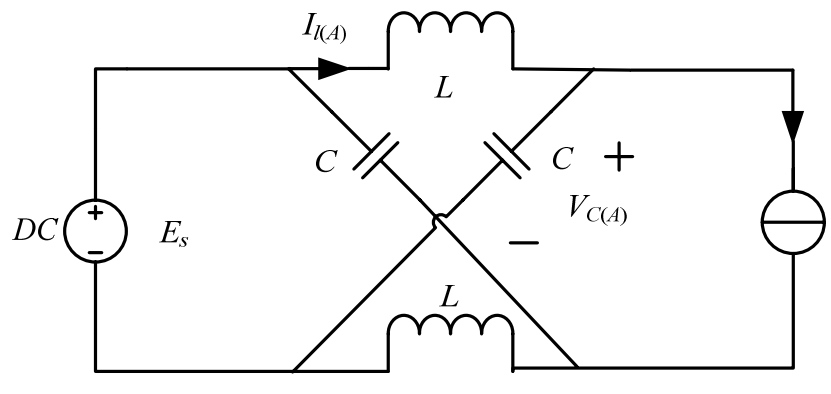

Active-1 State (A1)

(a)

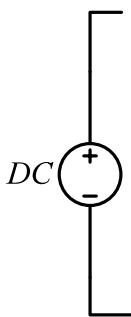

(b)

Six possible operation states of ZSI are identified in [12], among which Active-1, Open-1 and Shoot-through-1 States (named "dynamic states") contribute to the power conversion process. Since the Active-1 and Open-1 states behave in a similar manner, the Open-1 state could be considered as part of Active-1 state for analytical simplicity without introducing much error [12]. The other three operation states (named "static states") only occur when the capacitor voltage and inductor current fluctuate over a wide range. These three static states can be easily avoided by proper sizing of the Z-Source network components [12]. The following analysis is derived based on several assumptions: (1) switching frequency is high enough compared to output frequency; (2) Open-1 state could be considered as part of Active-1 state; (3) static states are avoided; (4) effects due to switch transitions are negligible. Since the inverter bridge itself has no energy storage elements, the instantaneous power input must equal the instantaneous power output:

$$
V_{d}(t) I_{d}(t)\left(1-d_{s}\right)=M V_{d}(t) \sin \omega t \cdot M \frac{V_{d}(t)}{|Z|} \sin (\omega t-\phi)
$$

where $V_{d}(t) I_{d}(t)$ stand for DC-link voltage and current, $d_{s}$ for shoot-through duty ratio, $M$ for modulation index, $Z$ and $\Phi$ for load impedance and power factor, $\omega$ for inverter output angular frequency. Note that the effects brought by switching frequency components are neglected. The term 
$\left(1-d_{s}\right)$ indicates that shoot-through state is not involved in energy transfer process from DC to AC side. Hence, DC side current drawn by the inverter bridge can be expressed as:

$$
I_{d}(t)=\frac{M^{2} V_{d}(t)}{2|Z|\left(1-d_{s}\right)} \cos \phi-\frac{M^{2} V_{d}(t)}{2|Z|\left(1-d_{s}\right)} \cos (2 \omega t-\phi)=\overline{I_{d}}+i_{d}(t)
$$

where $I_{d}$ (bar) and $i_{d}(t)$ denote the average and oscillating value of DC side current, respectively. Since this paper focuses on the design of a Z-Source network, the inverter bridge can be modeled as a current source $I_{d}(t)$, which is shown in right side of Figure 1. Equation (2) indicates that in addition to the DC component, the current also contains a sinusoidal component at twice the output frequency. The DC side current of a three-phase ZSI only contains the DC component, which solely results in high-frequency DC-link voltage ripple [12]. The situation of single-phase ZSI, nevertheless, is more complicated: (1) the DC component yields similar results to the three-phase case; (2) the sinusoidal component leads to a sinusoidal oscillation of the DC-link voltage, also at twice the output frequency. Therefore, both high and low frequency ripples need to be taken into consideration when sizing the Z-Source network.

\section{High-Frequency Ripple Analysis of Single-Phase ZSI}

High-frequency ripple analysis of single-phase ZSI should to be performed first in order to provide the operating point needed in low-frequency ripple analysis later. High-frequency ripple analysis of single-phase ZSI is essentially of the same pattern as that of three-phase ZSI presented in [12]. Effects related to low-frequency ripples could be temporarily neglected without much error since the allowed low-frequency ripple factors are usually small. During Shoot-through-1 (S-1) state, the diode gets reverse biased and energy is transferred from capacitors to inductors through these shoot-through switches (Figure 3a). If we assume that capacitor voltage and inductor current vary linearly with time instead of sinusoidal waveforms, peak ripple value of capacitor voltage $\Delta V_{c}(s)$ and peak ripple value of inductor current $\Delta I_{l}(s)$ during S-1 state could be expressed by:

$$
2 \Delta V_{c(s)}=\frac{\bar{I}_{l(s)} d_{s} 0.5 T_{s}}{C} \quad 2 \Delta I_{l(s)}=\frac{\bar{V}_{c(s)} d_{s} 0.5 T_{s}}{L}
$$

where $T_{s}$ stands for carrier time period, $L$ and $C$ for inductance and capacitance of Z-Source network, $E_{s}$ for DC source voltage, $V_{c(s)}\left(\right.$ bar) and $I_{l(s)}($ bar) for average value of capacitor voltage and inductor current during S-1 state.

During Active-1 (A-1) state, the diode gets forward biased and energy is transferred from DC source and inductors to load and capacitors (Figure 3b). Peak ripple value of capacitor voltage $\Delta V_{c(A)}$ and peak ripple value of inductor current $\Delta I_{l(A)}$ during A-1 state could be expressed by:

$$
2 \Delta V_{c(A)}=\frac{\left(\bar{I}_{l(A)}-\bar{I}_{d}\right)\left(1-d_{s}\right) 0.5 T_{s}}{C} \quad 2 \Delta I_{l(A)}=\frac{\left(\bar{V}_{c(A)}-E_{s}\right)\left(1-d_{s}\right) 0.5 T_{s}}{L}
$$

where $V_{c(A)}$ (bar) and $I_{l(A)}$ (bar) stand for average value of capacitor voltage and inductor current during A-1 state. Figure 4 shows the waveforms of capacitor voltage and inductor current analyzed above. 
Figure 4. Waveforms of capacitor voltage and inductor current for high-frequency ripple analysis.
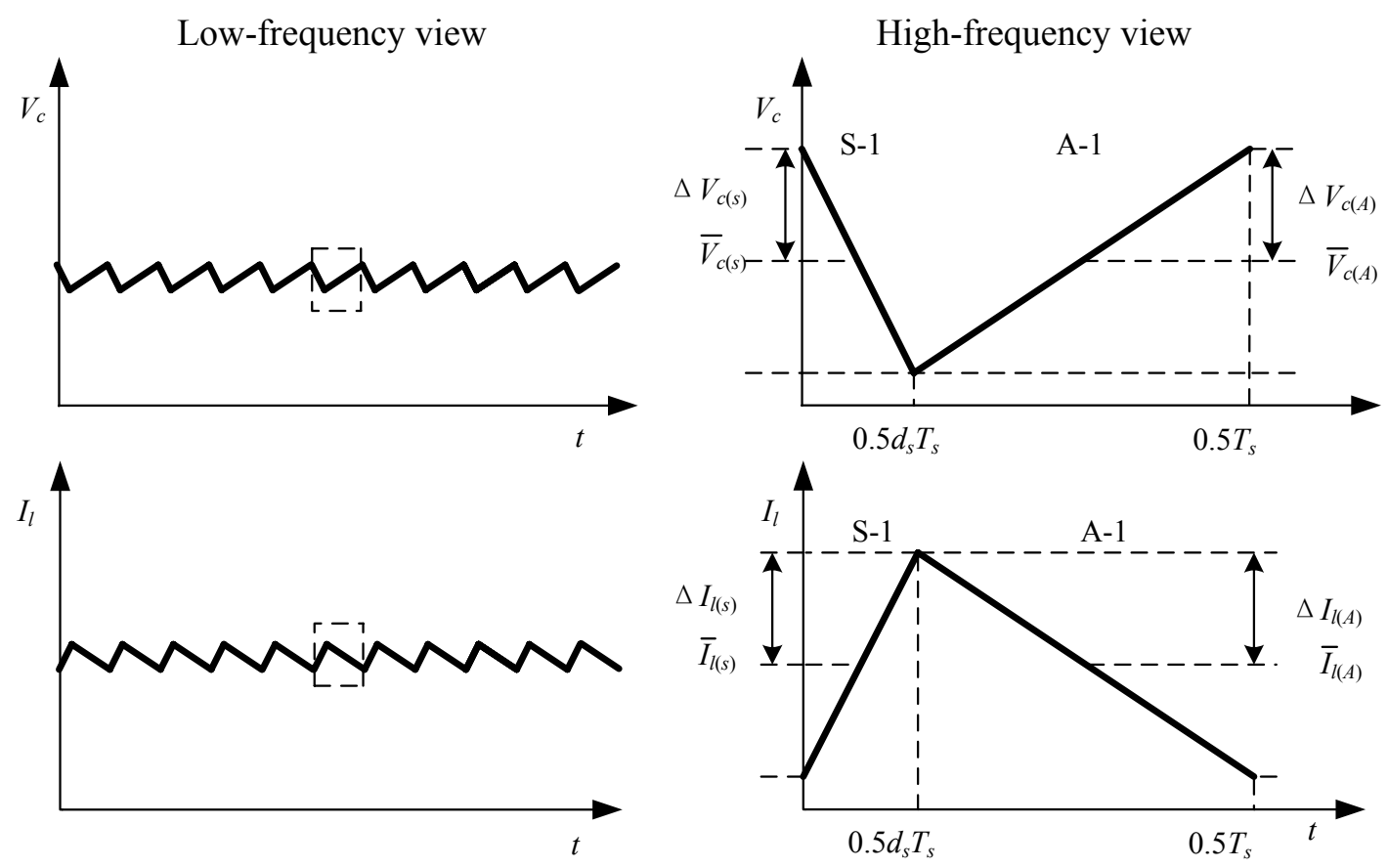

For steady-state operation, initial values of all variables equal their final values for every carrier cycle:

$$
\bar{V}_{c(A)}=\bar{V}_{c(s)}=\bar{V}_{c} \quad \Delta V_{c(A)}=\Delta V_{c(s)}=\Delta V_{c} \quad \bar{I}_{l(A)}=\bar{I}_{l(s)}=\bar{I}_{l} \quad \Delta I_{l(A)}=\Delta I_{l(s)}=\Delta I_{l}
$$

By combining (2)-(5), the average value of capacitor voltage and inductor current could be expressed as:

$$
\bar{V}_{c}=\frac{1-d_{s}}{1-2 d_{s}} E_{s} \quad \bar{I}_{l}=\frac{1-d_{s}}{1-2 d_{s}} \overline{I_{d}}
$$

High-frequency ripple factor of capacitor voltage and inductor current can be expressed as:

$$
k_{v c(H)}=\frac{\Delta V_{c}}{\bar{V}_{c}}=\frac{M^{2} d_{s} T_{s} \cos \phi}{8 C|Z|\left(1-d_{s}\right)\left(1-2 d_{s}\right)} \quad k_{i l(H)}=\frac{\Delta I_{l}}{\bar{I}_{l}}=\frac{\left(1-d_{s}\right)\left(1-2 d_{s}\right) d_{s} T_{s}|Z|}{2 L M^{2} \cos \phi}
$$

Both two high-frequency ripple factors should be limited in a narrow range for two major reasons. First, assumption (3) may be invalid since static states may occur when the capacitor voltage and inductor current vary over a wide range. In addition, smaller ripple factors are also desired in order to reduce the harmonic distortion of inverter output voltage, which is an important issue in $V 2 G$ applications. However, smaller ripple factors also mean larger capacitors and inductors. Therefore, a trade-off has to be made here by the designer while choosing the ripple factors.

If we define $k_{v c(H) 1}$ as the targeted high-frequency ripple factor set by the designer, high-frequency ripple factor of capacitor voltage $k_{v c(H)}$ should be smaller than $k_{v c(H) 1}\left(k_{v c(H)} \leq k_{v c(H) 1}\right)$. Likewise, high-frequency ripple factor of inductor current $k_{i l(H)}$ should be smaller than $k_{i l(H) 1}$ chosen by the designer $\left(k_{i l(H)} \leq k_{i l(H) 1}\right)$. Hence, the critical capacitance and inductance can be obtained by: 


$$
C \geq \frac{M^{2} d_{s} T_{s} \cos \phi}{8 k v_{c(H) 1}|Z|\left(1-d_{s}\right)\left(1-2 d_{s}\right)} \quad L \geq \frac{\left(1-d_{s}\right)\left(1-2 d_{s}\right) d_{s} T_{s}|Z|}{2 k_{i l(H) 1} M^{2} \cos \phi}
$$

During Active-1 State, $V_{d}=2 V_{c}-E_{s}$ (refer to Figure 3a). Therefore, high-frequency ripple factor of DC-link voltage:

$$
k_{v(H)}=\frac{\Delta V_{d}}{\bar{V}_{d}}=\frac{M^{2} d_{s} T_{s} \cos \phi}{4 C|Z|\left(1-2 d_{s}\right)}
$$

\section{Low-Frequency Ripple Analysis of Single-Phase ZSI}

As mentioned above, low-frequency ripples of single-phase ZSI originate in the oscillating component of the DC side current. Therefore, the major objective of low-frequency ripple analysis is to calculate the corresponding low-frequency oscillating component of capacitor voltage, inductor current and DC-link voltage caused by $i_{d}(t)$, respectively.

Base on the operating point given in high-frequency ripple analysis, capacitor voltage, inductor current and DC-link voltage can be expressed by:

$$
V_{c}(t)=\bar{V}_{c}+v_{c}(t) \quad I_{l}(t)=\bar{I}_{l}+i_{l}(t) \quad V_{d}(t)=\bar{V}_{d}+v_{d}(t)
$$

where $v_{c}(t) i_{l}(t) v_{d}(t)$ are corresponding low-frequency oscillations. Hence, based on Equation (2) DC side current could be modified as:

$$
I_{d}(t) \approx \frac{M^{2} \bar{V}_{d}}{2|Z|\left(1-d_{s}\right)} \cos \phi-\frac{M^{2} \bar{V}_{d}}{2|Z|\left(1-d_{s}\right)} \cos (2 \omega t-\phi)+\frac{M^{2} v_{d}(t)}{2|Z|\left(1-d_{s}\right)} \cos \phi=\bar{I}_{d}+i_{d}(t)
$$

During S-1 and A-1 state:

$$
\begin{gathered}
2 \Delta V_{c(s)}(t)=\frac{I_{l(s)}(t) d_{s} 0.5 T_{s}}{C} \quad 2 \Delta I_{l(s)}(t)=\frac{V_{c(s)}(t) d_{s} 0.5 T_{s}}{L} \\
2 \Delta V_{c(A)}(t)=\frac{\left(I_{l(A)}(t)-\bar{I}_{d}-i_{d}(t)\right)\left(1-d_{s}\right) 0.5 T_{s}}{C} \quad 2 \Delta I_{l(A)}(t)=\frac{\left(V_{c(A)}(t)-E_{s}\right)\left(1-d_{s}\right) 0.5 T_{s}}{L}
\end{gathered}
$$

Figure 5 shows the waveforms of capacitor voltage and inductor current for low-frequency ripple analysis.

Therefore, capacitor voltage and inductance voltage variation for one carrier period:

$$
\Delta V_{c 1}(t)=2 \Delta V_{c(A)}(t)-2 \Delta V_{c(s)}(t) \quad \Delta I_{l 1}(t)=2 \Delta I_{l(A)}(t)-2 \Delta I_{l(s)}(t)
$$

Assuming $V_{c(A)}(t)=V_{c(s)}(t)=V_{c}(t)$ and $I_{l(A)}(t)=I_{l(s)}(t)=I_{l}(t)$ yields:

$$
\begin{gathered}
\frac{\Delta V_{c 1}(t)}{0.5 T_{s}}=\frac{i_{l}(t)\left(1-2 d_{s}\right)-i_{d}(t)\left(1-d_{s}\right)}{C} \stackrel{T_{s} \rightarrow 0}{\longrightarrow} \frac{d v_{c}(t)}{d t}=\frac{i_{l}(t)\left(1-2 d_{s}\right)-i_{d}(t)\left(1-d_{s}\right)}{C} \\
\frac{-\Delta I_{l 1}(t)}{0.5 T_{s}}=\frac{-v_{c}(t)\left(1-2 d_{s}\right)}{L} \stackrel{T_{s} \rightarrow 0}{\longrightarrow} \frac{d i_{l}(t)}{d t}=-\frac{v_{c}(t)\left(1-2 d_{s}\right)}{L}
\end{gathered}
$$

Solving Equations (15) (16) yields: 


$$
\begin{aligned}
& v_{c}(t)=\frac{\omega M^{2} L \bar{V}_{d}}{\sqrt{4 \omega^{2} M^{4} \cos ^{2} \phi L^{2}+|Z|^{2}\left(4 \omega^{2} L C-\left(1-2 d_{s}\right)^{2}\right)^{2}}} \sin (2 \omega t+\theta) \\
& i_{l}(t)=\frac{M^{2}\left(1-2 d_{s}\right) \bar{V}_{d}}{2 \sqrt{4 \omega^{2} M^{4} \cos ^{2} \phi L^{2}+|Z|^{2}\left(4 \omega^{2} L C-\left(1-2 d_{s}\right)^{2}\right)^{2}}} \cos (2 \omega t+\theta) \\
& \theta=\tan ^{-1}\left(\frac{\left(1-2 d_{s}\right)^{2}|Z| \sin \phi-4 \omega^{2} L C|Z| \sin \phi+2 \omega M^{2} L \cos ^{2} \phi}{-\left(1-2 d_{s}\right)^{2}|Z| \cos \phi+4 \omega^{2} L C|Z| \cos \phi+2 \omega M^{2} L \sin \phi \cos \phi}\right)
\end{aligned}
$$

Low-frequency ripple factors of capacitor voltage and inductor current:

$$
\begin{aligned}
& k_{v c(L)}=\frac{\omega M^{2} L}{\left(1-d_{s}\right) \sqrt{4 \omega^{2} M^{4} \cos ^{2} \phi L^{2}+|Z|^{2}\left(4 \omega^{2} L C-\left(1-2 d_{s}\right)^{2}\right)^{2}}} \\
& k_{i l(L)}=\frac{\left(1-2 d_{s}\right)^{2}|Z|}{\cos \phi \sqrt{4 \omega^{2} M^{4} \cos ^{2} \phi L^{2}+|Z|^{2}\left(4 \omega^{2} L C-\left(1-2 d_{s}\right)^{2}\right)^{2}}}
\end{aligned}
$$

Figure 5. Waveforms of capacitor voltage and inductor current for low-frequency ripple analysis.

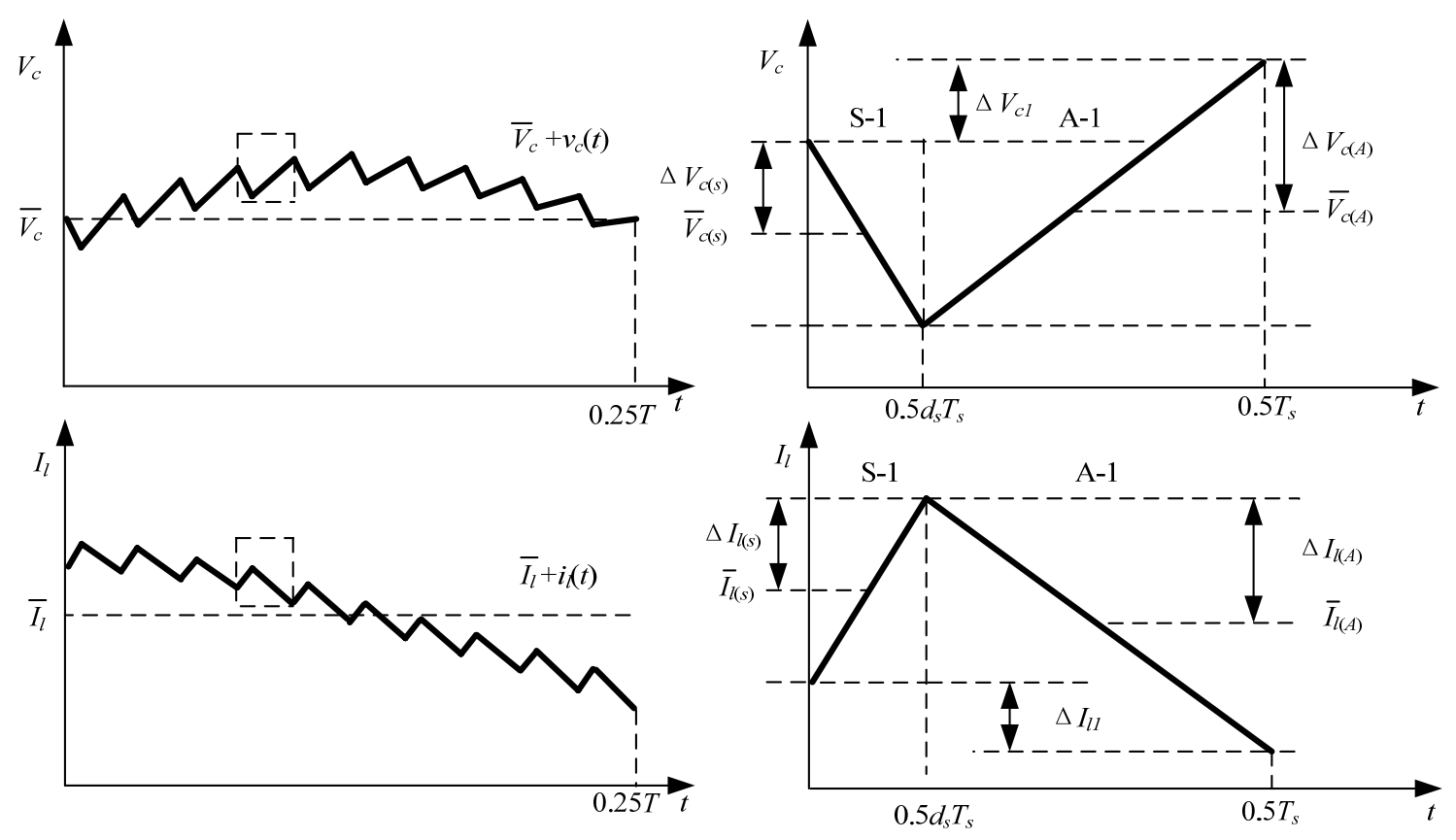

Finally, the low-frequency DC-link voltage ripple factor is given by:

$$
k_{v(L)}=\frac{2 \omega M^{2} L}{\sqrt{4 \omega^{2} M^{4} \cos ^{2} \phi L^{2}+|Z|^{2}\left(4 \omega^{2} L C-\left(1-2 d_{s}\right)^{2}\right)^{2}}}
$$

\section{Z-Source Network Design Approach}

Based on above analysis, a detailed design approach of Z-Source network of single-phase ZSI is presented with both high-frequency and low-frequency ripple constraints taken into consideration. Since the paper focuses on Z-Source network design, only the required capacitance $C$ and inductance $L$ 
are taken as the design output variables. On the other hand, low (high) frequency DC-link voltage ripple factor is proportional to low (high) frequency capacitor voltage ripple factor (refer to Equations (7) and (9), (18) and (19), respectively). Therefore, the input variables of the design procedure in Figure 6 should include:

- targeted high-frequency capacitor voltage ripple factor $k_{v c(H) 1}$

- targeted high-frequency inductor current ripple factor $k_{i l(H) 1}$

- targeted low-frequency capacitor voltage ripple factor $k_{v c(L) 1}$

- targeted low-frequency inductor current ripple factor $k_{i l(L) 1}$

The design procedure includes the following steps:

(1) calculating $\mathrm{C}$ based on $k_{v c(H) 1}$ constraint

(2) calculating $\mathrm{L}$ based on $k_{i l(H) 1}$ constraint

(3) checking whether $k_{v c(L) 1}$ constraint is met, modifying $C$ if not

(4) checking whether $k_{i l(L) 1}$ constraint is met, modifying $L$ if not

Figure 6. Detailed design procedure of a Z-Source network.

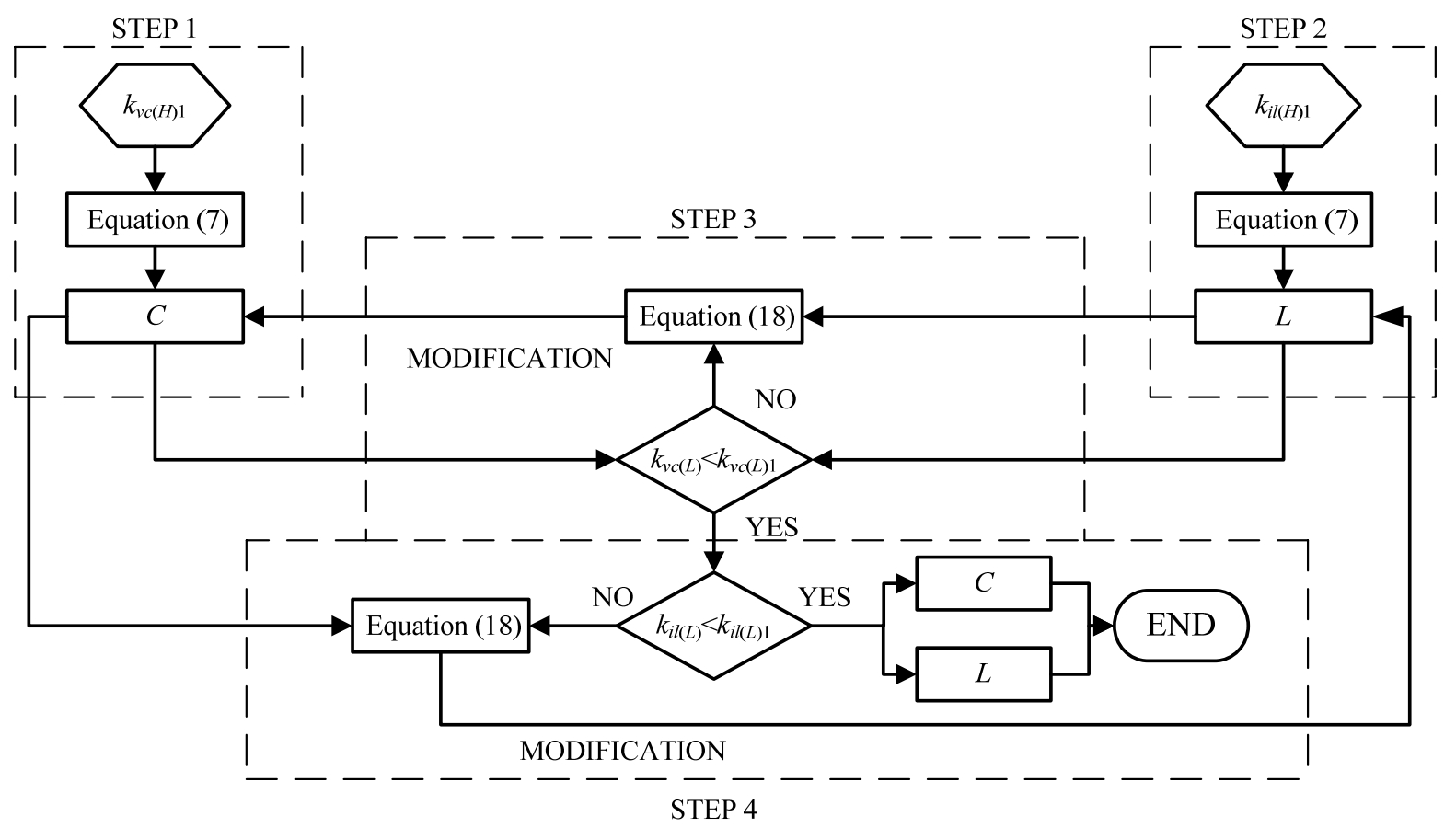

One single-phase ZSI (as Table 1) adopting Simple Boost Control [2] is presented as a design example. To meet four different groups of design requirements, the corresponding Z-Source network design results are listed in Table 2. Computer simulation results attained using Matlab/Simulink are also provided (Figure 7) to verify the effectiveness of the proposed design procedure. It is notable that the discrepancy existing between design and simulation increases with ripple factor.

Simulation low-frequency capacitor voltage ripple factor is calculated by:

$$
k_{v c(L) \text { simu }}=\frac{\text { measured maximum voltage }- \text { measured minimum voltage }}{\text { measured maximum voltage }+ \text { measured minimum voltage }}
$$


Table 1. Parameters of designed single-phase ZSI.

\begin{tabular}{|c|c|c|c|c|c|}
\hline $\begin{array}{c}\text { Output } \\
\text { Voltage/ } \\
\text { Frequency }\end{array}$ & $\begin{array}{c}\text { DC Source } \\
\left(\boldsymbol{E}_{\boldsymbol{s}}\right)\end{array}$ & $\begin{array}{c}\text { Load Resistance/ } \\
\text { Inductance }\end{array}$ & $\begin{array}{c}\text { Carrier } \\
\text { Frequency } \\
\left(\boldsymbol{f}_{\boldsymbol{s}}\right)\end{array}$ & $\begin{array}{c}\text { Shoot-through } \\
\text { Duty Ratio }\left(\boldsymbol{d}_{\boldsymbol{s}}\right)\end{array}$ & $\begin{array}{c}\text { Modulation } \\
\text { Index }(\boldsymbol{M})\end{array}$ \\
\hline $55 \mathrm{~V} / 50 \mathrm{~Hz}$ & $70 \mathrm{~V}$ & $10 \Omega / 2 \mathrm{mH}$ & $10 \mathrm{kHz}$ & 0.1 & 0.8889 \\
\hline
\end{tabular}

Table 2. Z-Source network design results.

\begin{tabular}{|c|c|c|c|c|c|c|c|}
\hline \multicolumn{4}{|c|}{ Design Input } & & \multicolumn{2}{|c|}{ Design Output } & Simulation Comparison \\
\hline$k_{v c(H) 1}$ & $k_{i l(H) 1}$ & $k_{i l(L) 1}$ & $k_{v c(L) 1}$ & $\left(k_{v(L)}\right)$ & $L / \mathrm{mH}$ & $C / \mathrm{uF}$ & $k_{v c(L)}$ \\
\hline \multirow{4}{*}{$2 \%$} & \multirow{4}{*}{$2 \%$} & \multirow{4}{*}{$10 \%$} & $1.00 \%$ & $(1.80 \%)$ & 2.29 & 7679 & $0.96 \%$ \\
\hline & & & $1.50 \%$ & $(2.70 \%)$ & 2.29 & 5355 & $1.40 \%$ \\
\hline & & & $2.00 \%$ & $(3.60 \%)$ & 2.29 & 4192 & $1.79 \%$ \\
\hline & & & $3.00 \%$ & $(5.40 \%)$ & 2.29 & 3029 & $2.50 \%$ \\
\hline
\end{tabular}

Figure 7. Simulation waveforms of capacitor voltage.

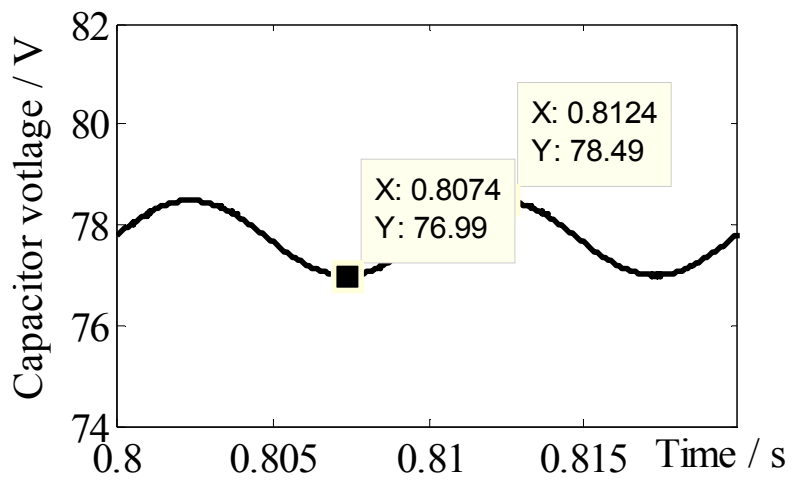

(a) $L=2.29 \mathrm{mH}, C=7679 \mathrm{uF}$

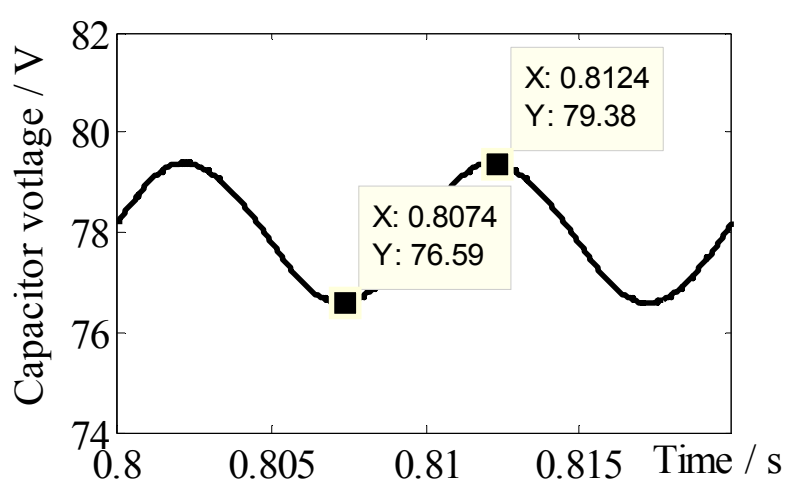

(c) $L=2.29 \mathrm{mH}, C=4129 \mathrm{uF}$

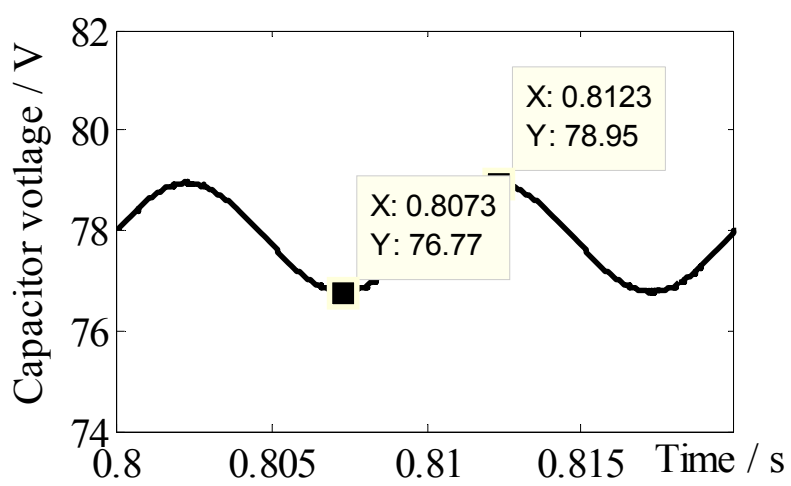

(b) $L=2.29 \mathrm{mH}, C=5355 \mathrm{uF}$

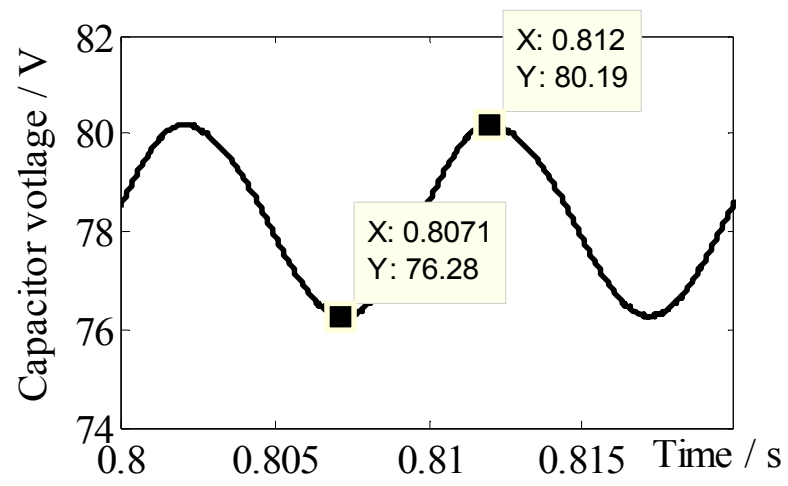

(d) $L=2.29 \mathrm{mH}, C=3029 \mathrm{uF}$

\section{Experimental Verification}

The same parameters as the simulation (Table 1) are used for the laboratory prototype. For illustration of the accuracy of the proposed design approach, the low-frequency capacitor voltage ripple factor is both theoretically calculated and experimentally measured for individual groups of Z-Source network ( $L$ and $C$ ) combinations. Experimental results are summarized in Table 3 and Figure 8 and shown in detail in Figure 9. The experimental low-frequency capacitor voltage ripple factor is calculated by: 


$$
k_{v c(L) \exp }=\frac{\text { measured peak to peak ripple }}{2 \times \text { measured average voltage }}
$$

Table 3. Comparison between theoretical predictions and experimental results.

\begin{tabular}{|c|c|c|c|}
\hline \multicolumn{2}{|c|}{ Z-Source Network Parameters } & Low-Frequency Capacitor Voltage Ripple Factor $\boldsymbol{k}_{\boldsymbol{v c}(\boldsymbol{L})}$ \\
\hline $\boldsymbol{L} / \mathbf{m H}$ & $\mathbf{C} / \mathbf{u F}$ & Theoretical Predictions & Experimental Results \\
\hline 2.29 & 2700 & $3.49 \%$ & $3.09 \%$ \\
2.29 & 3640 & $2.38 \%$ & $2.24 \%$ \\
2.29 & 4580 & $1.80 \%$ & $1.97 \%$ \\
2.29 & 5400 & $1.49 \%$ & $1.41 \%$ \\
2.29 & 6340 & $1.24 \%$ & $1.27 \%$ \\
2.29 & 7280 & $1.06 \%$ & $1.10 \%$ \\
\hline
\end{tabular}

Figure 8. Comparison between theoretical predictions and experimental results.

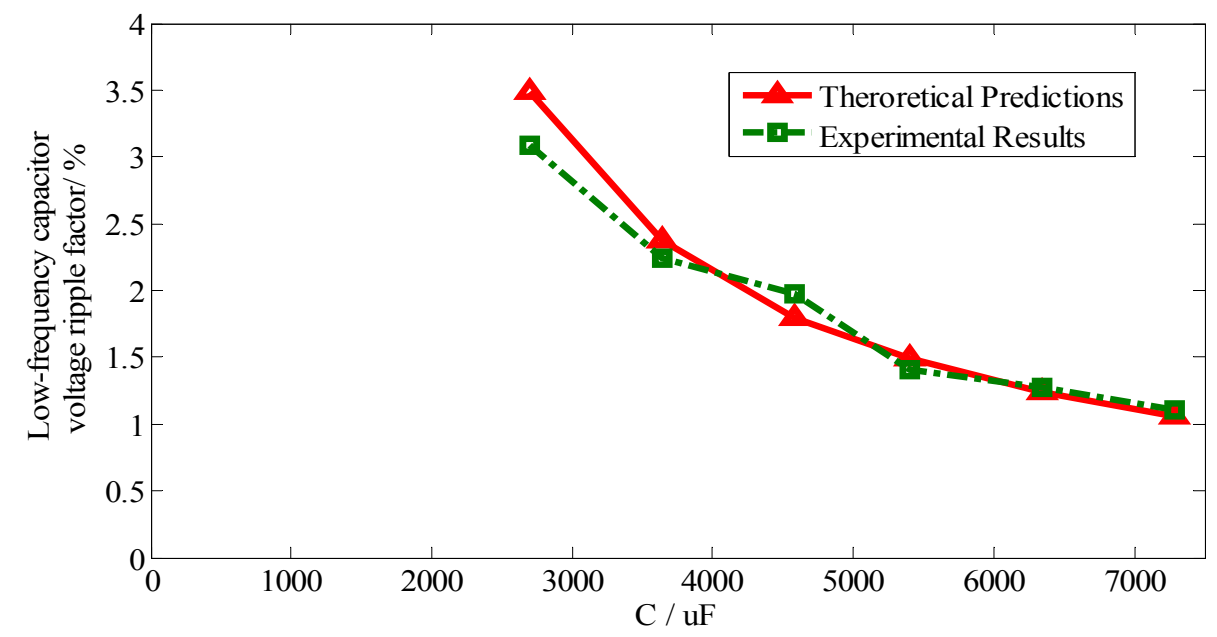

Figure 9. Experimental waveforms of DC source voltage (blue) $(10 \mathrm{~V} /$ div $)$, inverter output voltage (green) $(25 \mathrm{~V} /$ div) and capacitor voltage (red) $(1 \mathrm{~V} /$ div) (AC coupling) with different groups of $L$ and $C$ combinations; measured peak to peak ripple of capacitor voltage (a) $4.80 \mathrm{~V}$, (b) $3.48 \mathrm{~V}$, (c) $3.08 \mathrm{~V}$, (d) $2.20 \mathrm{~V}$, (e) $1.98 \mathrm{~V}$, (f) $1.72 \mathrm{~V}$; measured average capacitor voltage (a) $77.57 \mathrm{~V}$, (b) $77.83 \mathrm{~V}$, (c) $78.15 \mathrm{~V}$, (d) $78.03 \mathrm{~V}$, (e) $78.01 \mathrm{~V}$, (f) $78.11, \mathrm{~V}$.

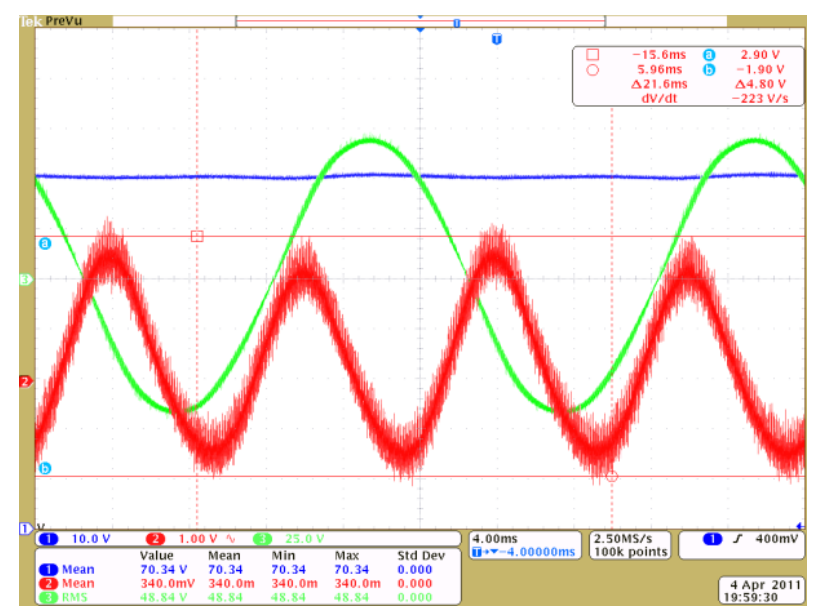

(a) $L=2.29 \mathrm{mH}, C=2700 \mathrm{uF}$

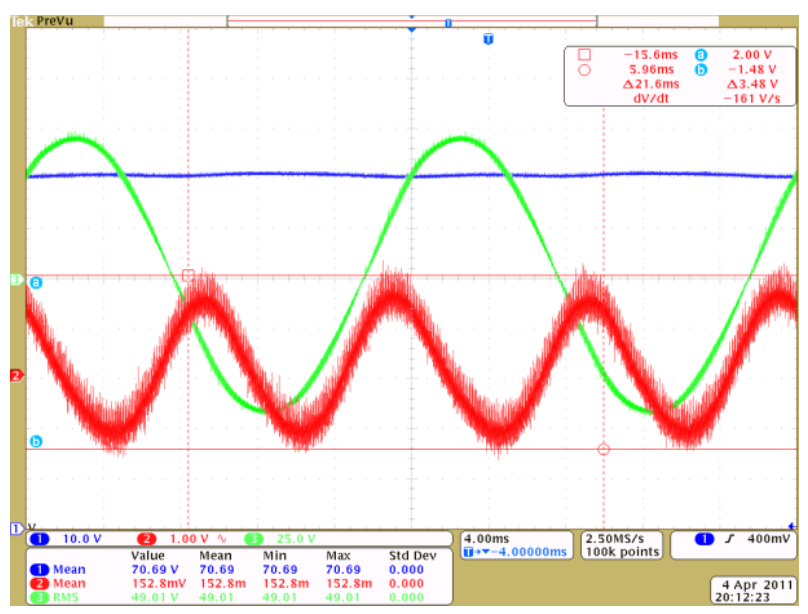

(b) $L=2.29 \mathrm{mH}, C=3640 \mathrm{uF}$ 
Figure 9. Cont.

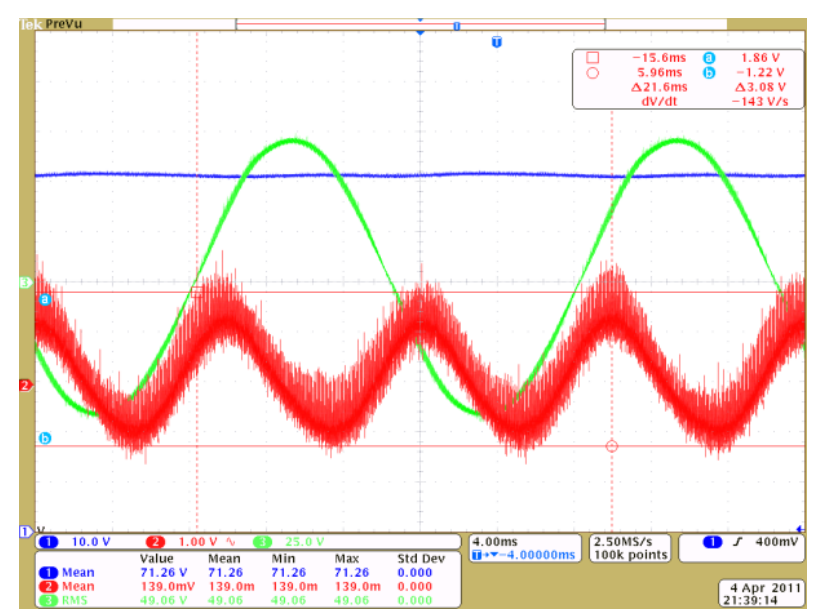

(c) $L=2.29 \mathrm{mH}, C=4580 \mathrm{uF}$

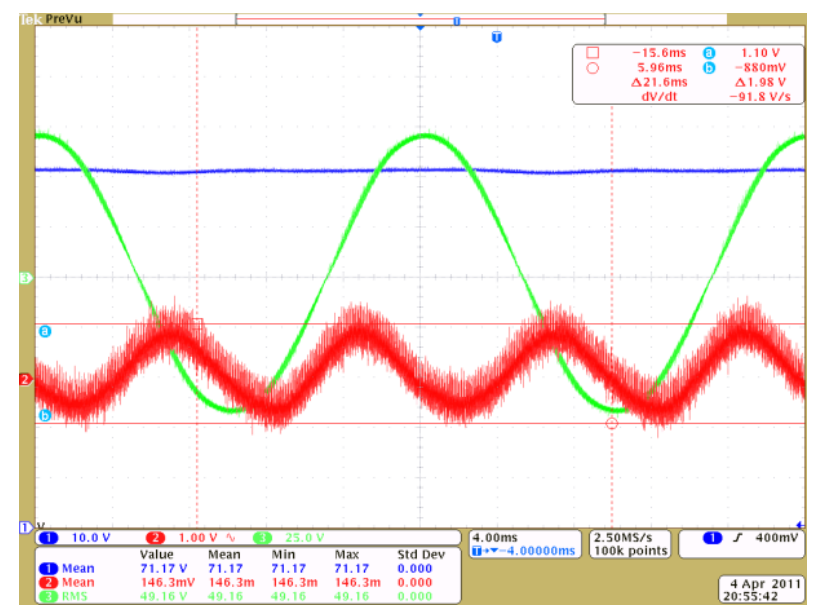

(e) $L=2.29 \mathrm{mH}, C=6340 \mathrm{uF}$

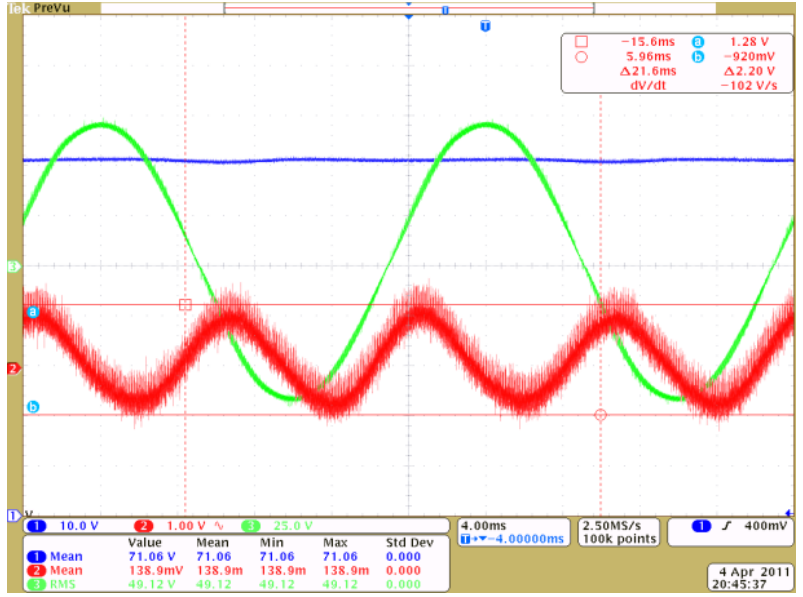

(d) $L=2.29 \mathrm{mH}, C=5400 \mathrm{uF}$

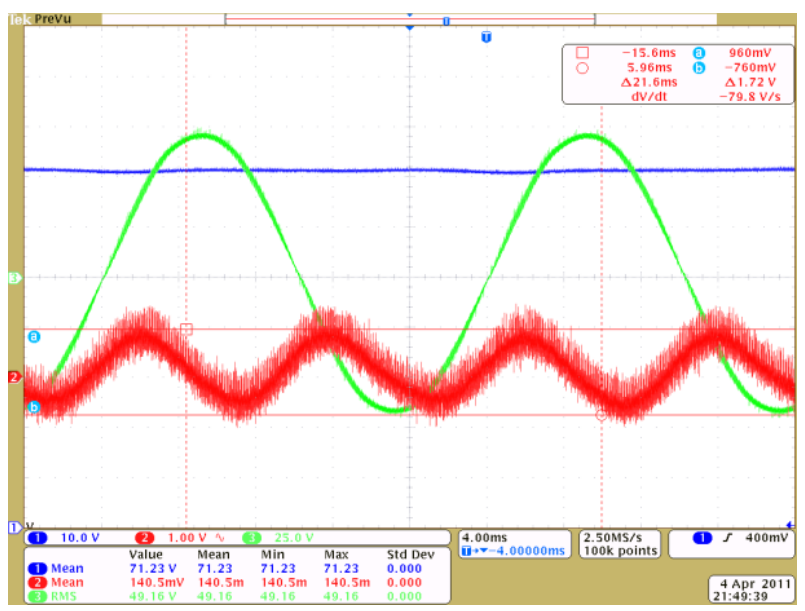

(f) $L=2.29 \mathrm{mH}, C=7280 \mathrm{uF}$

From Table 3 and Figure 8, it is noted that the accuracy of proposed design method is acceptable for small ripples, but deteriorates with larger ripples, which is expected from the computer simulation. This observed feature indicates that for large ripple factor design cases, the design results obtained by theoretical calculation need further modification by simulation or experimental test. The cause of this phenomenon could be explained by that the accuracy of linear approximation deteriorates with increasing ripple.

\section{Conclusions}

In this paper, Z-Source network design rules of a single-phase Z-Source inverter for batteries discharging of Vehicle to Grid applications are proposed based on limiting the low-frequency ripples within an acceptable range. Computer simulation and experimental results are provided to verify the effectiveness of the proposed design method. For small ripple design cases, the presented design method is of acceptable accuracy. For large ripple factor design cases, the design results obtained by theoretical calculation may need further modification by simulation or experimental tests. Possible contributing factors to the existing discrepancy for large ripple factor include the assumption that linear approximation accurate enough. 


\section{Acknowledgments}

This research work is funded by Project HIT.NSRIF.2009042 supported by Natural Scientific Research Innovation Foundation of Harbin Institute of Technology and Project 2009RFLXG010 supported by Innovation Funding for Returned Overseas Chinese Scholars in Harbin.

\section{References}

1. Madawala, U.K.; Thrimawithana, D.J. A bidirectional inductive power interface for electric vehicles in V2G systems. IEEE Trans. Ind. Electron. 2011, 58, 4789-4796.

2. Peng, F.Z. Z-Source Inverter. IEEE Trans. Ind. Appl. 2003, 39, 504-510.

3. Peng, F.Z.; Shen, M.; Qian, Z. Maximum boost control of the Z-Source inverter. IEEE Trans. Power Electron. 2005, 20, 833-838.

4. Shen, M.; Wang, J.; Joseph, A.; Peng, F.Z.; Tolbert, L.M.; Adams, D.J. Constant boost control of the Z-Source inverter to minimize current ripple and voltage stress. IEEE Trans. Ind. Appl. 2006, 42, 770-778.

5. Yang, S.; Ding, X.; Peng, F.Z.; Qian, Z. Unified Control Technique for Z-Source Inverter. In Proceedings of the 39th IEEE Annual Power Electronics Specialists Conference, Rhodes, Greece, 15-19 June 2008; pp. 3236-3242.

6. Liu, J.; Hu, J.; Xu, L. Dynamic modeling and analysis of $\mathrm{Z}$ source converter: Derivation of AC small signal model and design-oriented analysis. IEEE Trans. Power Electron. 2007, 22, 1786-1796.

7. Tang, Y.; Xie, S.; Zhang, C.; Xu, Z. Improved Z-Source inverter with reduced Z-source capacitor voltage stress and soft-start capability. IEEE Trans. Power Electron. 2009, 24, 409-415.

8. Anderson, J.; Peng, F.Z. Four Quasi-Z-Source Inverters. In Proceedings of the 39th IEEE Annual Power Electronics Specialists Conference, Rhodes, Greece, 15-19 June 2008; pp. 2743-2749.

9. Li, Y.; Anderson, J.; Peng, F.Z.; Liu, D. Quasi-Z-Source Inverter for Photovoltaic Power Generation Systems. In Proceedings of the 25th Annual IEEE Applied Power Electronics Conference and Exposition, Palm Springs, CA, USA, 21-25 February 2009; pp. 918-924.

10. Ding, X.; Qian, Z.; Yang, S.; Cui, B.; Peng, F.Z. A New Adjustable-Speed Drives (ASD) System Based on High-Performance Z-Source Inverter. In Proceedings of the 42th IEEE Annual Industrial Application Society Meeting, New Orleans, LA, USA, 23-27 September 2007; pp. 2327-2332.

11. Zhou, Z.J.; Zhang, X.; Xu, P.; Shen, W.X. Single-phase uninterruptible power supply based on Z-source inverter. IEEE Trans. Ind. Electron. 2008, 55, 2997-3004.

12. Rajakaruna, S.; Jayawickrama, L. Steady-state analysis and designing impedance network of Z-source inverters. IEEE Trans. Ind. Electron. 2010, 57, 2483-2491.

(C) 2011 by the authors; licensee MDPI, Basel, Switzerland. This article is an open access article distributed under the terms and conditions of the Creative Commons Attribution license (http://creativecommons.org/licenses/by/3.0/). 